\title{
FARINHAS DE SILAGEM DE RESÍDUO DE PESCADO CO-SECAS COM FARELO DE ARROZ: UMA ALTERNATIVA VIÁVEL
}

\author{
CO-DRIED FISH WASTE SILAGE MEAL AND RICE BRAN: A VIABLE ALTERNATIVE
}

\author{
Benites, C.I. ${ }^{1}$ e Souza-Soares, L.A. ${ }^{1,2}$
}

\begin{abstract}
${ }^{1}$ Fundação Universidade Federal do Rio Grande (FURG). Pós-graduação em Engenharia e Ciência de Alimentos. RuaEng. Alfredo Huch, 475.CEP 96201-900.Rio Grande/RS. Brasil.bele_benites@yahoo.com.br ${ }^{2}$ Universidade Federal de Pelotas (UFPel). Pelotas. Brasil. leonor.souzasoares@gmail.com
\end{abstract}

\section{PalaVRas ChaVe adicionais}

Umbrina canosai. Cynoscion guatacupa. Subprodutos.

\section{RESUMO}

Objetivou-se caracterizar a silagem de resíduo de castanha (Umbrina canosai) e de pescada (Cynoscion guatacupa) com adição de ácido acético e vinagre comercial, bem como o efeito da adição de farelo de arroz (FA) no processo de secagem. O preparo da silagem consistiu na moagem do resíduo, acidificação, homogeneização durante 5 dias e acompanhamento do $\mathrm{pH}$. Após 15 dias, as silagens foram centrifugadas, as frações sólidas obtidas foram secas em estufa, e moídas. Utilizou-se um planejamento experimental fatorial $2^{3}$ cujas variáveis e níveis foram: tipo de peixe, agente acidificante e coadjuvante de secagem (presença e ausência de FA). Observou-se que os lipídios das farinhas não apresentaram diferenças significativas, porém, a adição de FA diminuiu o teor de cinzas e proteínas, além do tempo de secagem, indicando melhoria do processo. A concentração do ácido não interferiu no produto obtido, assim como a espécie de peixe.

\section{SUMMARY}

Silages of fish wastes from castanha (Umbrina canosai) and pescada (Cynoscion guatacupa) were made with acid addition (acetic or vinegar) and rice bran as drying agent. The silage preparation consisted of the grinding waste, acidification, daily homogenization for five days and monitoring the $\mathrm{pH}$. After 15 days, the silages were centrifuged, dried in stove and ground. A $2^{3}$ factorial design was employed, in which the studied factors and levels were: fish species,

Recibido: 28-5-07. Aceptado: 28-6-07.

\section{AdDitional KEYWORDS}

Umbrina canosai. Cynoscion guatacupa. Byproducts.

acid agent and the presence of rice bran during the drying process. The lipids content weren't significantly different, however, the addition of rice bran reduced considerably the ash content and shorted the drying time, indicating improvement of the process. It was verified that the concentration of acid and the fish species didn't interfere in the product.

\section{INTRODUÇÃO}

Os resíduos de pescado pode chegar até 70\% da matéria-prima. Seu aproveitamento pode minimizar os custos e a poluição ambiental. Atualmente, estes resíduos são utilizados para fabricação de farinha de pescado, entretanto problemas como: a falta de cuidado no seu armazenamento, o tempo de permanência dos resíduos nas unidades coletoras, a dificuldade no transporte e o tipo de tratamento que o resíduo sofre, leva a um produto sem higiene e de baixa qualidade nutricional.

Uma alternativa é a silagem, que origina um produto liquefeito a partir dos resíduos, espécies subutilizadas ou impróprias para o consumo. Possui alto valor biológico e é preservada pela redução do $\mathrm{pH}$ através de ácidos, enzimas ou microorganismos (Vidotti et al., 2003) além disto, agrega valor e previne problemas ambientais, econômicos

Arch. Zootec. 59 (227): 447-450. 2010. 
e de saúde da população, possibilitando melhor qualidade nutricional, devido ao tratamento mais brando e higiênico, sem tempo de residência do resíduo.

A adição de ingredientes vegetais minimiza os custos, agregando valor e qualidade nutricional, dependendo de sua digestibilidade e características físico-químicas (Hossain et al., 1997). O farelo de arroz (FA) possui baixo valor comercial, é empregado na alimentação animal e rico nutricionalmente. O objetivo deste trabalho foi elaborar farinhas de silagem químicas ácidas, a partir de resíduos de pescados marinhos, avaliando a ação do agente acidificante, a viabilidade de emprego de FA como coadjuvante de secagem e conseqüente potencial de utilização como complemento para rações animais.

\section{MATERIAL EMÉTODOS}

Utilizou-se o ácido acético pelo baixo custo e por não atingir um $\mathrm{pH}$ muito baixo ao final do processo, diminuindo a necessidade de neutralização do produto, também foi estudada a utilização do vinagre comercial.

No preparo da silagem (figura 1), utilizaram-se os resíduos de duas espécies de grande captura: castanha (Umbrina canosai) e pescada (Cynoscion guatacupa), constituídos de cabeças, vísceras, escamas e cauda, que foram moídos e acidificados com: ácido acético (87\%) a 10\% p/v e vina-

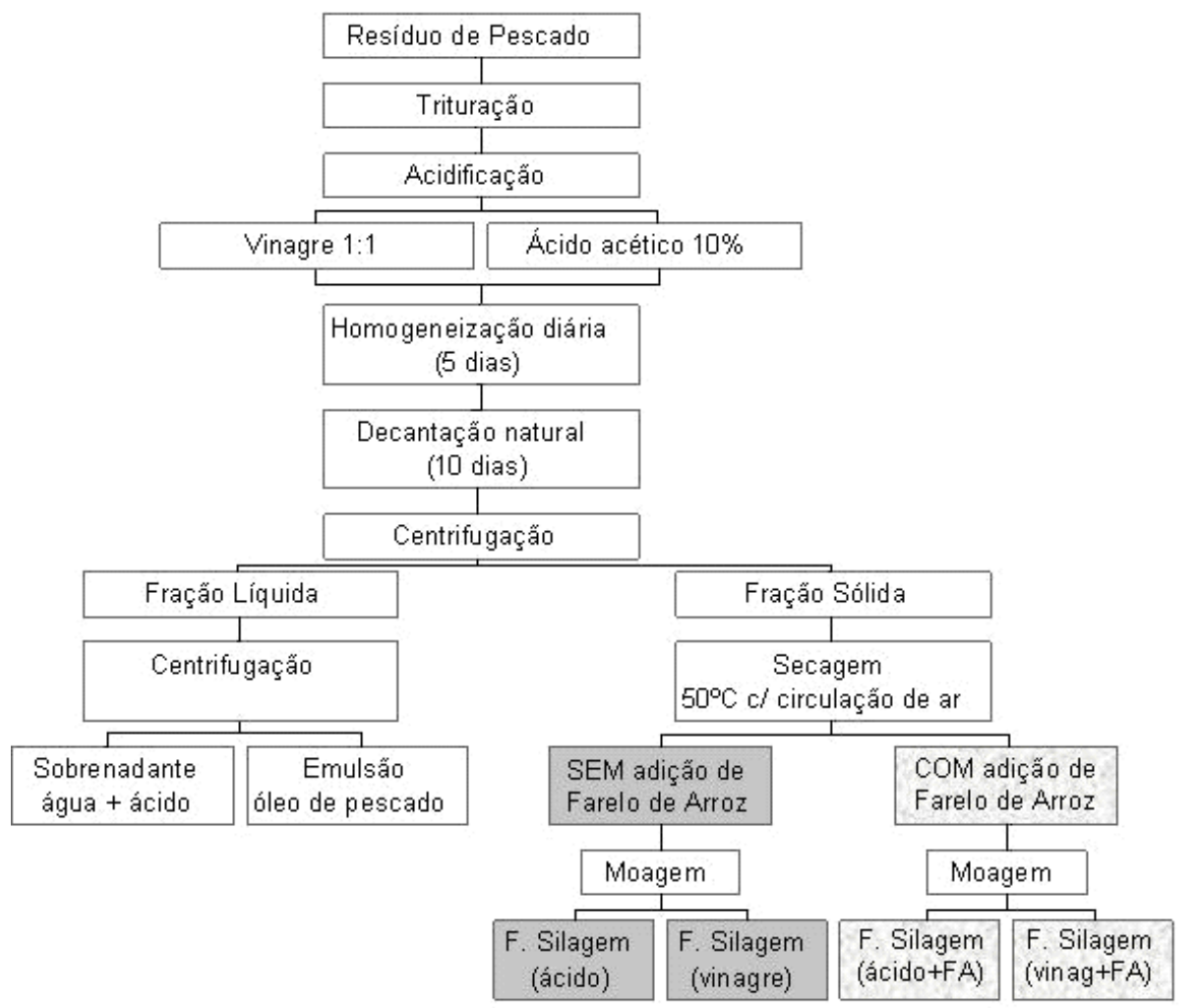

Figura 1. Fluxograma de obtenção das farinhas de silagem. (Flowchart of obtain of ensilage meals).

Archivos de zootecnia vol. 59, núm. 227, p. 448. 
gre comercial (4\% ácido acético 1:1 p/v). O material foi armazenado, à temperatura ambiente, em recipientes plásticos com tampa, homogeneizado durante os 5 dias iniciais e com acompanhamento diário de pH. Após a centrifugação, separou-se as frações: líquida (sobrenadante e emulsão), e sólida. A emulsão foi colocada em banho-maria (overnight), liberando óleo de pescado. Uma alíquota da fração sólida foi seca de forma pura e outra, foi acrescentado FA integral (1:3) antes da secagem (estufa, $50^{\circ} \mathrm{C}$, com circulação de ar).

No delineamento (fatorial $2^{3}$ ), estudouse a influência das 3 variáveis na obtenção das farinhas de silagem (FS): tipo de peixe, agente acidificante e coadjuvante de secagem. Para a análise estatística, utilizouse teste de Tukey (ANOVA-Statistica). Assim, neste processo obteve-se 8 farinhas: C1 (castanha e ác. acético); C2 (castanha e vinagre); $\mathrm{C} 1_{\mathrm{FA}}$ (castanha e ác. acético + FA); $\mathrm{C} 2_{\mathrm{FA}}$ (castanha e vinagre $+\mathrm{FA}$ ); $\mathrm{P} 1$ (pescada e ác. acético); P2 (pescada e vinagre); P1 (pescada e ác. acético + FA); $\mathrm{P} 2_{\mathrm{FA}}$ (pescada e vinagre + FA).

Nos resíduos (RC e RP) foram analisados: bases voláteis totais (BVT), trimetilamina (TMA) (extração, LANARA, 1981; e recolhimento por destilação), $\mathrm{pH}$ e composição (umidade, minerais totais, proteína bruta) segundo AOAC (1995) e lipídios totais (Bligh e Dyer, 1959). Nas FS a composição proximal foi com os mesmos métodos e digestibilidade protéica in vitro, com pepsina e pancreatina (Augusto-Ruiz, 1982).

\section{RESULTADOSEDISCUSSÃO}

Na análise do frescor, o RC apresentou BVT e TMA= 68 e 48,2 mg/100 g de amostra, e RP respectivamente, 94 e $77 \mathrm{mg} / 100 \mathrm{~g}$, indicando maior degradação. $\mathrm{O}$ pH inicial foi 6,0 e para as silagens foram: C1 3,9; C2 4,2; P1 3,9; P2 4,5. O tipo de peixe não interferiu no $\mathrm{pH}$, mas o agente acidificante foi crucial, pois o vinagre não se equiparou $(\mathrm{p}<0,05)$ ao ácido. Com vinagre o $\mathrm{pH}$ chegou a 4,5, o ponto crítico para o crescimento de patógenos, para Costa et al. (2006) a utilização do vinagre foi eficaz no máximo 32 dias. $\mathrm{O} \mathrm{pH}<4,0$ resulta em segurança microbiológica, sendo que o ideal é que não haja desperdício do agente acidificante, nem prejuízo na estabilidade. Nunes (2001) verificou que é viável a diminuição de ácido acético para $10 \%$ p/v. Neste trabalho, o vinagre apresentou uma ação satisfatória no início do período de ensilagem, assim, sua utilização depende do tempo de silagem e de ambiente acima de $25^{\circ} \mathrm{C}$, para agilizar a hidrólise.

O rendimento de centrifugação foi diferente (p<0,05) C1 75\%; C2 56\%; P1 39\% e P2 $28 \%$, a maior parte do material se liquefez, pela ação do vinagre. A relação ao peixe, com pescada apresentou menor quantidade de sólidos, ficando mais liquefeita. No rendimento de secagem, os tratamentos com FA, apresentaram-se maiores (média de 49,3\%) em relação a FS pura (média 36,7\%), pois FA adsorve a silagem, sendo superiores aos 25-26\% de Seibel e Souza-Soares (2003). Para Goddard e Perret (2005), a silagem líquida pode ser combinada diretamente na dieta ou seca para o uso como um ingrediente de rações, sendo que a secagem utiliza muita energia, mas a estocagem na forma líquida, aumenta os custos de transporte e armazenamento. Assim, as pesquisas voltam-se para o uso de misturas entre as silagens de pescado adsorvidas em cereais, de forma que ocorra uma co-secagem e forme um ingrediente seco, sem prejuízo ao desempenho dos animais e reduzindo o custo (Carvalho et al., 2006).

A tabela I apresenta a composição das matérias-primas e das FS, observa-se que a presença do FA integral, devido ao seu teor de carboidratos, diminuiu proporcionalmente os demais nutrientes, além de aumentar o teor de lipídios. As diferenças se devem à composição das matérias-primas: Seibel e 


\section{BENITESE SOUZA-SOARES}

Tabela I. Composição proximal das matériasprimas e das farinhas e sua digestibilidade in vitro (\%). (Meals digestibility in vitro (\%) and composition (\%) of the same ones).

\begin{tabular}{|c|c|c|c|c|c|}
\hline & $U$ & $\mathrm{P}^{1}$ & $M^{1}$ & $\mathrm{~L}^{1}$ & D \\
\hline $\mathrm{RC}$ & $71,7^{b}$ & $55,2^{b}$ & $23,1^{\text {ef }}$ & $21,5^{\mathrm{a}}$ & - \\
\hline $\mathrm{RP}$ & $76,5^{a}$ & $66,3^{a}$ & $14,5^{\mathrm{g}}$ & $19,1^{\mathrm{ab}}$ & - \\
\hline $\mathrm{FA}$ & $11,7^{\mathrm{c}}$ & $12,1^{f}$ & $10,0^{\mathrm{h}}$ & $18,6^{b c}$ & - \\
\hline C1 & $8,8^{\text {de }}$ & $53,0^{b}$ & $30,7^{c}$ & $15,3^{d}$ & $94,0^{\mathrm{abc}}$ \\
\hline $\mathrm{C} 2$ & $6,8^{e}$ & $45,1^{d}$ & $38,8^{b}$ & $13,4^{d}$ & $96,7^{a}$ \\
\hline P1 & $12,6^{c}$ & $49,2^{c}$ & $23,3^{\text {ef }}$ & $13,9^{d}$ & $96,9^{a b}$ \\
\hline P2 & $9,9^{\text {cd }}$ & $43,7^{d}$ & $41,7^{a}$ & $9,9^{\mathrm{e}}$ & $94,9^{a b c}$ \\
\hline $\mathrm{C} 1_{\mathrm{FA}}$ & $7,8^{\text {de }}$ & $32,2^{\mathrm{e}}$ & $21,8^{\mathrm{e}}$ & $15,8^{\mathrm{cd}}$ & $95,7^{\mathrm{ab}}$ \\
\hline$C 2^{\mathrm{FA}}$ & $8,4^{\text {de }}$ & $31,0^{e}$ & $26,8^{d}$ & $15,4^{d}$ & $92,5^{b}$ \\
\hline$P 1_{F A}^{F A}$ & $9,8^{\mathrm{cd}}$ & $33,5^{\mathrm{e}}$ & $18,7^{f}$ & $20,1^{\mathrm{ab}}$ & $95,0^{\mathrm{abc}}$ \\
\hline$P 2_{F A}^{F A}$ & $10,0^{\text {cd }}$ & $31,7^{\mathrm{e}}$ & $25,6^{d}$ & $19,2^{\mathrm{ab}}$ & $93,4^{b c}$ \\
\hline
\end{tabular}

Médias de 3 repetições. Letras distintas na mesma coluna indicam diferença estatística $(p<0,05)$ de acordo com Teste de Tukey. ${ }^{1}$ base seca, $\mathrm{U}=$ umidade, $\mathrm{P}=$ proteínas, $\mathrm{M}=$ minerais, $\mathrm{L}=$ lipídios, $\mathrm{D}=$ digestibilidade, $\mathrm{R}=$ resíduo, $\mathrm{C}=$ castanha; $\mathrm{P}=$ pescada, $\mathrm{FA}=$ farelo de arroz, 1= ac. acético, 2= vinagre.

\section{BIBLIOGRAFIA}

AOAC. 1995. Official methods of analysis. $16^{\text {th }}$ edition. AOAC International. Virgínia.

Augusto-Ruiz, W. y Farfan, J.A. 1982. Hidrólisis enzimática del resíduo no soluble de la soya. Em: Seminario Latino Americano de Ciência y Tecnologia de Alimentos. Chile. pp. 127-135.

Bligh, E.G. and Dyer, W.J. 1959. A rapid method of total lipid extraction and purification. Can. J. Biochem. Physiol., 37: 911-917.

LANARA. 1981. Laboratório Nacional de Referência Animal. Métodos analíticos oficiais para o controle de produtos de origem animal e seus ingredientes. II-Métodos físicos e químicos. Ministério da Agricultura. Secretaria Nacional de Defesa Agropecuária. Brasília.

Carvalho, G.G.P., Pires, A.J.V., Veloso, C.M., Silva, F.F. e Carvalho, B.M.A. 2006. Silagem de resíduo de peixes em dietas para alevinos de tilápia-donilo. Rev. Bras. Zootecn., 35: 126-130.

Costa, C.S., Silva, L.A., Enke, D.B.S. y Alfaro, A.
Souza-Soares (2003) obtiveram 46,3-56,7\% de proteína, $11-14 \%$ de umidade, $16-18 \%$ de minerais e 13,6-14,5\% de lipídios para FS química de pescada; Goddard e Perret (2005) 48-58\% de proteína, 36-51\% de umidade, 14$17 \%$ de minerais e 7,5-8,6\% de lipídios em silagem ácida de sardinha indiana co-secas com farelo de trigo. O vinagre diminui o teor de proteínas e lipídios na farinha, indicando que podem estar solubilizados.

As digestibilidades in vitro (tabela I) apresentaram valores elevados, devido à hidrólise durante o processo. Isto é corroborado por Hossain et al. (1997), onde silagens ácidas com farelo de trigo apresentaram digestibilidade melhor que a farinha de pescado, respectivamente: $84-89 \%$ e 80 $84 \%$.

$O$ vinagre comercial pode ser utilizado na fabricação de silagem de pescado; a adição de FA foi vantajosa, otimizando a secagem; não havendo restrições quanto ao tipo de peixe, FS pura ou agregada ao FA, são produtos com grande potencial de utilização em rações mais nutritivas.

2006. Ensilado de Pescado. C\&A. Carne y Alimentos. 1: 27-34.

Goddard, J.S. and Perret, J.S.M. 2005. Co-drying fish silage for use in aquafeeds. Anim. Feed. Sci. Tech., 118: 337-342.

Hossain, M.A., Nahar, N. and Kamal, M. 1997. Nutrient digestibility coefficients of some plant and animal proteins for rohu (Labeo rohita). Aquaculture, 151: 37-45.

Nunes, J.A.R. 2001. Aproveitamento do rejeito da industrialização de pescado marinho a partir de silagem ácida. Dissertação (Mestrado). FURG. Rio Grande. 115 pp.

Seibel, N.F. e Souza-Soares, L.A. 2003. Produção de silagem química com resíduos de pescado marinho. Braz. J. Food. Tech., 6: 333-337.

Vidotti, R.M., Viegas, E.M.M. and Carneiro, D.J. 2003. Amino acid composition of processed fish silage using different raw materials. Anim. Feed. Sci. Tech., 105: 199-204.

Archivos de zootecnia vol. 59, núm. 227, p. 450. 